\title{
Corrigendum: Dynamic expression of long noncoding RNAs and repeat elements in synaptic plasticity
}

\begin{abstract}
Jesper L. V. Maag 1,2, Debabrata Panja ${ }^{3}$, Ida Sporild ${ }^{3}$, Sudarshan S. Patil ${ }^{3}$, Dominik C. Kaczorowski ${ }^{1}$, Clive R. Bramham ${ }^{3 *}$, Marcel E. Dinger ${ }^{1,2 *}$ and Karin Wibrand ${ }^{3 *}$

1 Genomics and Epigenetics Division, Garvan Institute of Medical Research, Sydney, NSW, Australia, ${ }^{2}$ Faculty of Medicine, St Vincent's Clinical School, University of New South Wales, Sydney, NSW, Australia, ${ }^{3}$ Department of Biomedicine and K.G.

Jebsen Centre for Research on Neuropsychiatric Disorders, University of Bergen, Bergen, Norway
\end{abstract}

Keywords: long noncoding RNA (IncRNA), LTP (long term potentiation), retrotransposons, repeat elements, rat brain, time-series data, synaptic plasticity (LTP/LTD)

\section{A corrigendum on}

Dynamic expression of long noncoding RNAs and repeat elements in synaptic plasticity

OPEN ACCESS

Edited and reviewed by: Igor Ponomarev

University of Texas at Austin, USA

*Correspondence:

Clive R. Bramham

clive.bramham@biomed.uib.no

Marcel E. Dinger

m.dinger@garvan.org.au Karin Wibrand

karin.wibrand@fys.uib.no

Specialty section: This article was submitted to

Neurogenomics,

a section of the journal

Frontiers in Neuroscience

Received: 12 July 2016

Accepted: 12 July 2016

Published: 27 July 2016

Citation

Maag JLV, Panja D, Sporild I, Patil SS, Kaczorowski DC, Bramham CR,

Dinger ME and Wibrand K (2016)

Corrigendum: Dynamic expression of long noncoding RNAs and repeat

elements in synaptic plasticity.

Front. Neurosci. 10:354.

doi: 10.3389/fnins.2016.00354 by Maag, J. L. V., Panja, D., Sporild, I., Patil, S., Kaczorowski, D. C., Bramham, C. R., et al. (2015). Front. Neurosci. 9:351. doi: 10.3389/fnins.2015.00351

Reason for Corrigendum:

There was a mistake in the accession number as published. The accession number in the published version is referred to as E-MTAB-2072 while the correct accession number is E-MTAB3375. The authors apologize for the mistake. This error does not change the scientific conclusions of the article in any way.

\section{AUTHOR CONTRIBUTIONS}

JM led the project and performed the bioinformatic analysis. DP conducted the electrophysiology experiments. SP contributed to electrophysiology. KW extracted the RNA and conducted qPCRs. IS contributed to RNA extraction. DK prepared the samples for RNA-sequencing. KW, JM, and MD designed the study. JM, KW, CB, and MD wrote the manuscript.

\section{FUNDING}

This work was supported by the Research Council of Norway (grants 204861 and 199355), Bergen Medical Research Foundation, and the University of Bergen (KW).

Conflict of Interest Statement: The authors declare that the research was conducted in the absence of any commercial or financial relationships that could be construed as a potential conflict of interest.

Copyright $\odot 2016$ Maag, Panja, Sporild, Patil, Kaczorowski, Bramham, Dinger and Wibrand. This is an open-access article distributed under the terms of the Creative Commons Attribution License (CC BY). The use, distribution or reproduction in other forums is permitted, provided the original author(s) or licensor are credited and that the original publication in this journal is cited, in accordance with accepted academic practice. No use, distribution or reproduction is permitted which does not comply with these terms. 